\title{
Combined Environment Simulator for Low-Dose-Rate Radiation and Partial Gravity of Moon and Mars
}

\author{
Akihisa Takahashi ${ }^{1, *(\mathbb{D})}$, Sakuya Yamanouchi ${ }^{1}$, Kazuomi Takeuchi ${ }^{2}$, Shogo Takahashi ${ }^{2}$,

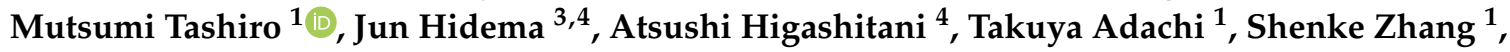 \\ Fady Nagy Lotfy Guirguis ${ }^{1}{ }^{\oplus}$, Yukari Yoshida ${ }^{1}$, Aiko Nagamatsu ${ }^{5}$, Megumi Hada ${ }^{6}{ }^{\circledR}$, \\ Kunihito Takeuchi ${ }^{2}$, Tohru Takahashi ${ }^{2}$ and Yuji Sekitomi ${ }^{2,7}$ \\ 1 Gunma University Heavy Ion Medical Center, 3-39-22 Showa-machi, Maebashi, Gunma 371-8511, Japan; \\ 3ra9di8o.y@gmail.com (S.Y.); tashiro@gunma-u.ac.jp (M.T.); skywatcher.tak@gmail.com (T.A.); \\ m1920602@gunma-u.ac.jp (S.Z.); fadynagy.lotfy@yahoo.com (F.N.L.G.); yyukari@gunma-u.ac.jp (Y.Y.) \\ 2 Matsuo Industries, Inc., 27-1, Ida, Kitasaki-machi, Obu, Aichi 474-0001, Japan; \\ ka-takeuchi@kk-matsuo-ss.co.jp (K.T.); s-takahashi@kk-matsuo-ss.co.jp (S.T.); \\ k-takeuchi@kk-matsuo-ss.co.jp (K.T.); t-takahashi@kk-matsuo-ss.co.jp (T.T.); \\ y-sekitomi@kk-matsuo-ss.co.jp (Y.S.) \\ 3 Division for the Establishment of Frontier Sciences of the Organization for Advanced Studies, Tohoku \\ University, 2-1-1 Katahira, Aoba-ku, Sendai, Miyagi 980-8577, Japan; j-hidema@ige.tohoku.ac.jp \\ 4 Graduate School of Life Sciences, Tohoku University, 2-1-1 Katahira, Aoba-ku, Sendai, \\ Miyagi 980-8577, Japan; atsushi.higashitani.e7@tohoku.ac.jp \\ 5 Japan Aerospace Exploration Agency, Tsukuba Space Center, 2-1-1 Sengen, Tsukuba, Ibaraki 305-8505, Japan; \\ nagamatsu.aiko@jaxa.jp \\ 6 Radiation Institute for Science \& Engineering, Prairie View A\&M University, Prairie View, TX 77446, USA; \\ mehada@pvamu.edu \\ 7 Material Solutions Center, Tohoku University, 2-1-1 Katahira, Aoba-ku, Sendai, Miyagi 980-8577, Japan \\ * Correspondence: a-takahashi@gunma-u.ac.jp; Tel.: +81-27-220-7917
}

Received: 23 September 2020; Accepted: 4 November 2020; Published: 6 November 2020

\begin{abstract}
Deep space exploration by humans has become more realistic, with planned returns to the Moon, travel to Mars, and beyond. Space radiation with a low dose rate would be a constant risk for space travelers. The combined effects of space radiation and partial gravity such as on the Moon and Mars are unknown. The difficulty for such research is that there are no good simulating systems on the ground to investigate these combined effects. To address this knowledge gap, we developed the Simulator of the environments on the Moon and Mars with Neutron irradiation and Gravity change (SwiNG) for in vitro experiments using disposable closed cell culture chambers. The device simulates partial gravity using a centrifuge in a three-dimensional clinostat. Six samples are exposed at once to neutrons at a low dose rate ( $1 \mathrm{mGy} /$ day) using Californium-252 in the center of the centrifuge. The system is compact including two SwiNG devices in the incubator, one with and one without radiation source, with a cooling function. This simulator is highly convenient for ground-based biological experiments because of limited access to spaceflight experiments. SwiNG can contribute significantly to research on the combined effects of space radiation and partial gravity.
\end{abstract}

Keywords: combined effect; low-dose-rate radiation; partial gravity; simulator; Moon; Mars; neutron

\section{Introduction}

NASA has planned to return to the Moon by 2024 with a mission named Artemis. The mission will start building the Lunar Gateway and aims to be a trial for deeper space exploration. It will be an important step for landing humans on Mars. It is necessary to develop a simulator of the environments 
on the Moon and Mars because the difference environment of space radiation and gravity condition in deep space as compared with Low Earth Orbit (LEO).

Space radiation environment is one of major risk factor in long-term exploration by humans. During LEO, the astronauts are protected from various space radiation by the Earth's magnetic field. When they fly into the deep space, they need to pass through the trapped radiation belt composed with electrons and protons, and will be constantly exposed to solar particle events (SPEs) and galactic cosmic rays (GCRs), including high-energy heavy ions, without protection [1]. The longer the astronauts stay in deep space, the more the exposure to space radiation will be increased. No current spacecraft or spacesuit can shield astronauts from these energetic cosmic rays. Therefore, we need the ground-based experiments to simulate the space radiation environment. We can use the high-energy heavy-ion accelerators at specialized facilities such as the BEVALAC at the Lawrence Berkeley National Laboratory, the Heavy Ion Medical Accelerator in Chiba (HIMAC) at the National Institute of Radiological Sciences of the National Institutes for Quantum and Radiological Science and Technology (QST-NIRS), the GSI Helmholtz Center for Heavy Ion Research (GSI), and our Gunma University Heavy Ion Center (GHMC) [2] to expose biological samples. The majority of studies performed at these facilities were acute exposure of single radiation, fractioned doses, or combined sequential beams. In the NASA Space Radiation Laboratory (NSRL) at Brookhaven National Laboratory (BNL), SPE and GCR simulated beam can be used by rapid switching technology of ion species and ion energies [3]. Although we know that dose rates of space radiation are very low, it is challenging to perform exposure experiments with a low dose rate owing to the limited beam time allowed at such facilities. Recently, a concrete-shielded building on the campus of Colorado State University (CSU) was retrofitted with a panoramic Californium-252 $\left({ }^{252} \mathrm{Cf}\right)$ source to allow low-dose-rate irradiation. The shielded vault can accommodate caging to simultaneously irradiate 900 mice and 60 rats for durations up to 400 days at a neutron dose rate of 1 mGy/day [4]. Long-term exposure to neutrons is a potential health hazard when astronauts encounter GCRs during their missions outside Earth's magnetosphere. Despite that neutrons constitute a small proportion of GCRs, secondary neutrons ejected owing to interaction between GCRs and the shield elements are significant $[5,6]$. A major indicator is that the dose-averaged linear energy transfer (LET) of the low-dose-rate neutrons directly emitted from the ${ }^{252} \mathrm{Cf}$ on Earth is close to that of the highly charged ions in space radiation. Furthermore, owing to the fundamental impact of primary and secondary scattered photons, high-energy neutrons emitted from ${ }^{252} \mathrm{Cf}$ decomposition resemble the secondary ionizations of delta particle beams emitted from heavier high-energy charged particles [7]. Although they are a good substitute for the complex radiations that would be encountered in deep space, this ground experiment is in Earth's gravity of $9.81 \mathrm{~ms}^{-2}(1 G)$.

Partial gravity environments on the Moon and Mars are important to promote life science research, not only simulates microgravity $(\mu G)$ in spaceflight environments. Advanced ground-based systems for simulating gravity alterations have made it possible to study the response of living beings to altered gravity to prepare for experiments in space. Media that reduce vertical acceleration to the partial gravity of the Moon $(0.165 G \fallingdotseq 1 / 3 G)$ and Mars $(0.378 G \fallingdotseq 3 / 8 G)$ or other celestial body can achieve the $\mu G$ level or weightlessness [8]. Although a ballistic rocket, parabolic flight, or drop tower can produce a $\mu G$ environment for free fall on the Earth, the disadvantages of these approaches are the limited time of exposing to $\mu G$ and the additional hypergravity. To simulate $\mu G$, researchers have used rotating devices such as the Rotating Wall Vessel bioreactor (RWV: Synthecone, Houston, TX, USA) and the Random Positioning Machine (RPM: Dutch Space, Netherlands). These are components of devices that revolve the sample in an uninterrupted manner. These machines can oppose and balance the direction of gravity and diminish its impact, inducing $\mu G$ [2]. Two main drawbacks to this concept are (i) revolution stops amid irradiation because the sample is susceptible to irradiation outside the incubator after or before rotation with an RWV [9-13], and (ii) the dose flatness in the irradiation area is non-uniform owing to irradiation from outside an RPM [14,15]. To deal with these limitations, we developed the System of Simultaneous irradiation in Simulated- $\mu$ G (SSS) using a three-dimensional (3D) clinostat $[16,17]$. 
The SSS relies on X-ray irradiation with a high-speed shutter [16], and on carbon-ion irradiation with radiological technologies like accelerator systems and respiratory gating systems [17].

More than 50 years ago, a relatively large centrifuge outfitted with clinostats was used for experiments simulating partial gravity [18]. Other researchers applied a simple angled or inclined clinostat to generate partial gravity [19,20], and systems like centrifuge-clinostats were constructed [21,22]. Recently, researchers have developed devices using the RPM to simulate partial gravity [8]. As a next step, we need to investigate the effects of partial gravity on the biological response to radiation for manned missions to the Moon and Mars and compare them with those of both simulated $\mu G$ and Earth gravity $(1 G)$.

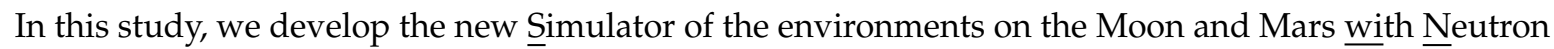
irradiation and Gravity change (SwiNG) (Figure 1).

A

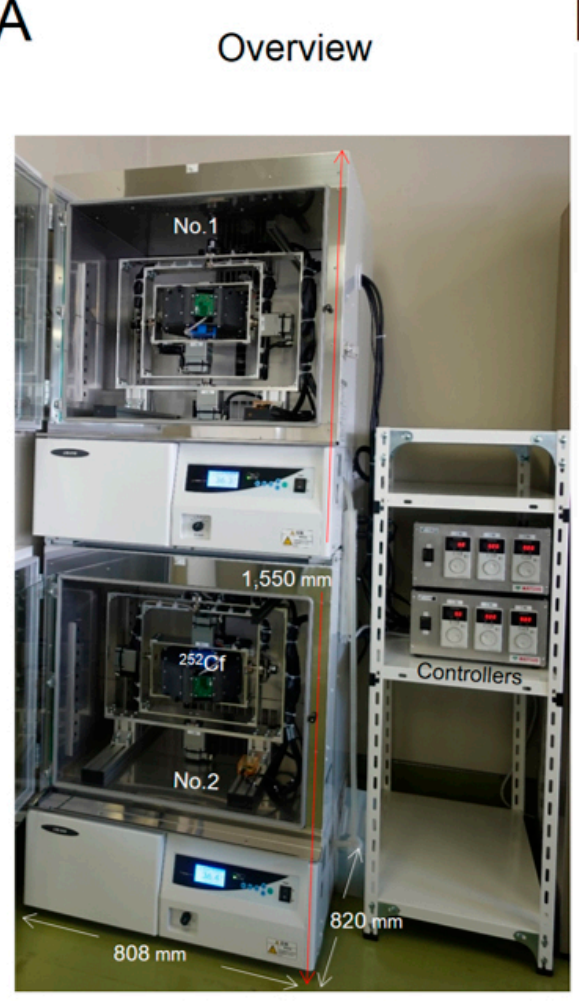

B

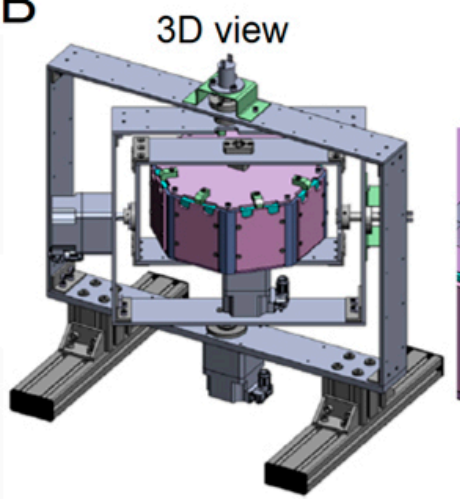

Front view

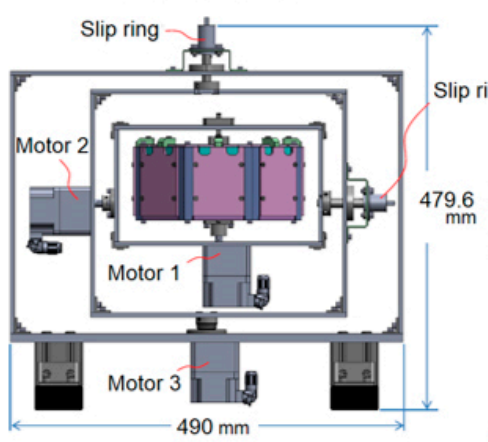

Inside view

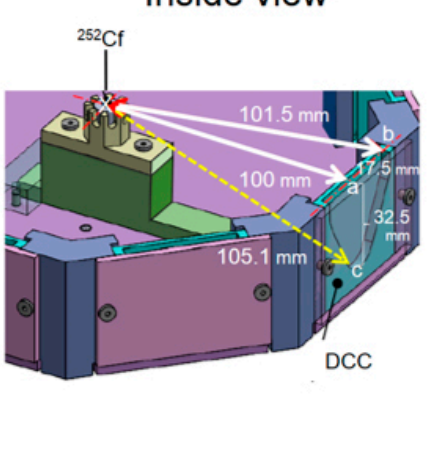

Side view

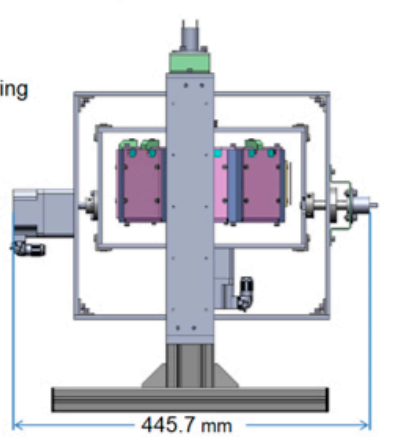

C
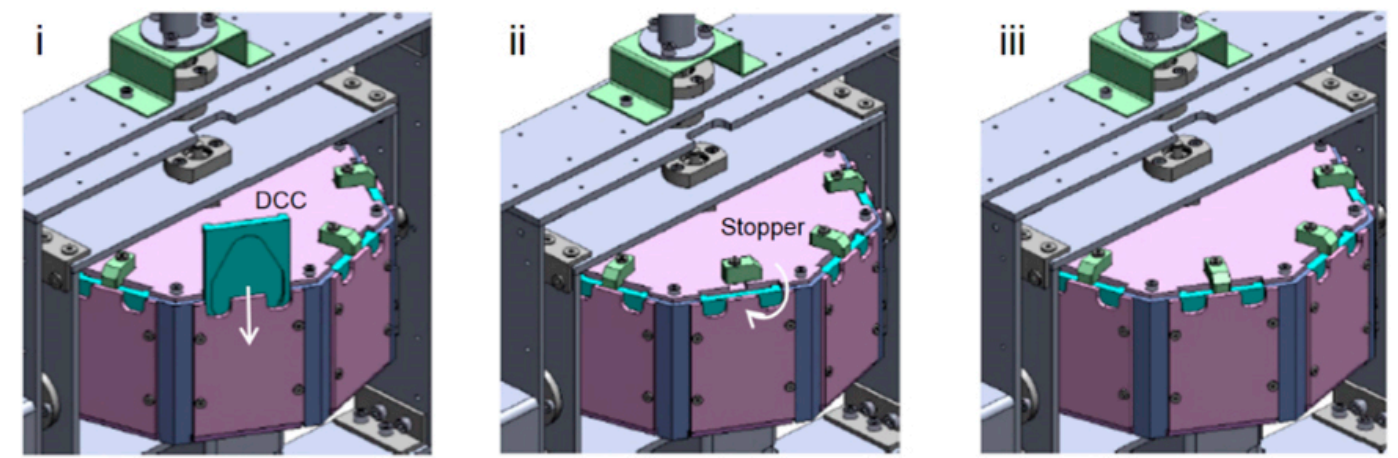

Figure 1. Schema of the Simulator of the environments on the Moon and Mars with Neutron irradiation and Gravity change (SwiNG). (A) Overview. (B) Outside view, and inside view of the rotor, where " $x$ " is the radiation source, and " $a$ " is the center, " $b$ " is the short end, and " $c$ " is the long end of the disposable closed cell culture chamber (DCC). (C) Setting a culture chamber in the rotor, which consists of (i) injecting the DCC and (ii) turning the stopper, after which (iii) the installation is complete. 


\section{Materials and Methods}

\subsection{System Descriptions}

The simulator is comprised of five subsystems: (1) a 3D clinostat, (2) a centrifuge, (3) a radiation source, (4) a sample chamber [23], and (5) an incubator. Its specifications are summarized in Table 1. The compact system (W $808 \mathrm{~mm} \times$ D $820 \mathrm{~mm} \times$ H $1550 \mathrm{~mm}$ ) has two SwiNG devices, one with and one without a ${ }^{252} \mathrm{Cf}$ source in the incubators with a cooling function.

Table 1. Specifications of the Simulator of the environments on the Moon and Mars with Neutron irradiation and Gravity change (SwiNG).

\begin{tabular}{|c|c|}
\hline Subsystem & Specifications \\
\hline 3D clinostat & $\begin{array}{l}\text { External size: W } 490 \mathrm{~mm} \times \mathrm{D} 445.7 \mathrm{~mm} \times \mathrm{H} 479.6 \mathrm{~mm} \\
\text { Rotational velocity: } 66^{\circ} / \mathrm{s} \text { and } 78^{\circ} / \mathrm{s} \\
\text { Manufacturer: Matsuo Industries, Inc. (Aichi, Japan) }\end{array}$ \\
\hline Centrifuge & $\begin{array}{l}\text { Rotor size: W } 216 \mathrm{~mm} \times \text { D } 216 \mathrm{~mm} \times \text { H } 90 \mathrm{~mm} \text { (octagonal type) } \\
\text { Speed control range: } 27-133 \mathrm{rpm} \\
\text { Manufacturer: Matsuo Industries, Inc. }\end{array}$ \\
\hline Radiation source & $\begin{array}{l}{ }^{252} \mathrm{Cf}(\mathrm{N}-252 \mathrm{CE} \text {, Japan Radioisotope Association, Tokyo, Japan) } \\
\text { External size: Diameter } 9.4 \mathrm{~mm} \times \mathrm{L} 36.3 \mathrm{~mm} \\
\text { Dose-equivalent average energy: } 2.3 \mathrm{MeV} \\
\text { Dose-averaged LET: } 68 \mathrm{keV} / \mu \mathrm{m} \\
\text { Half-life: } 2.645 \text { years }\end{array}$ \\
\hline Sample chamber & $\begin{array}{l}\text { Disposable closed cell culture chamber (DCC, Chiyoda Co., Kanagawa, Japan) } \\
\text { External size: } \mathrm{W} 86.0 \mathrm{~mm} \times \mathrm{D} 50.0 \mathrm{~mm} \times \mathrm{H} 7.3 \mathrm{~mm} \\
\text { Cultivation area: } 15.5 \mathrm{~cm}^{2}(\mathrm{~W} 65 \mathrm{~mm} \times \mathrm{D} 35 \mathrm{~mm}) \\
\text { Liquid depth: } 3 \mathrm{~mm} \\
\text { Material: polystyrene (bottom thickness: } 1 \mathrm{~mm} \text {; top thickness: } 50 \mu \mathrm{m}) \\
\text { Six DCCs can be placed in the rotor }\end{array}$ \\
\hline Incubator & $\begin{array}{l}\text { Low-temperature incubator without control of } \mathrm{CO}_{2} \text { concentrations: LTE-510 } \\
\text { (Tokyo Rikakikai Co., Tokyo, Japan) } \\
\text { Internal size: } \mathrm{W} 600 \mathrm{~mm} \times \mathrm{D} 500 \mathrm{~mm} \times \mathrm{H} 500 \mathrm{~mm} \\
\text { Temperature control range/accuracy: }-10-60{ }^{\circ} \mathrm{C} / \pm 0.2{ }^{\circ} \mathrm{C}\end{array}$ \\
\hline
\end{tabular}

\subsection{Neutron Source}

We calculated the amount of ${ }^{252} \mathrm{Cf}$ required to provide a space-relevant dose rate of $1 \mathrm{mGy} /$ day according to Borak et al. [4]. The shielding guide DP-1246 quotes the fission neutron yield as $2.4 \times 10^{12} \mathrm{~s}^{-1} \mathrm{~g}^{-1}$ with a corresponding photon yield of $1.3 \times 10^{13} \mathrm{~s}^{-1} \mathrm{~g}^{-1}$ [24]. The configuration of the facility was based on a panoramic irradiator encircled by a disposable closed cell culture chamber (DCC) at a radius of $100 \mathrm{~mm}$ from the radiation source. DP-1246 was used to estimate the initial quantity of ${ }^{252} \mathrm{Cf}$ (neutron) required to provide a space-relevant dose rate of $1 \mathrm{mGy} /$ day. Using the neutron yield for ${ }^{252} \mathrm{Cf}$, the fluence rate at $100 \mathrm{~mm}(\Phi \mathrm{n})$ is

$$
\Phi \mathrm{n}=2.4 \times 10^{12} \mathrm{~s}^{-1} \mathrm{~g}^{-1} \div(4 \pi \times 100 \mathrm{~mm} \times 100 \mathrm{~mm})=19.1 \times 10^{6} \mathrm{~mm}^{-2} \mathrm{~s}^{-1} \mathrm{~g}^{-1}
$$

DP-1246 lists the dose rate conversion factor $(\mathrm{Kn})$ for soft tissue in a phantom approximating a man as

$$
K \mathrm{n}=1.43 \times 10^{-2} \mathrm{mGy} \mathrm{h}^{-1} \mathrm{~mm}^{2} \mathrm{~s}
$$

The neutron dose rate at $100 \mathrm{~mm}(\mathrm{Dn})$ would be

$$
D n=\Phi n \times K n=19.1 \times 10^{6} \mathrm{~mm}^{-2} \mathrm{~s}^{-1} \mathrm{~g}^{-1} \times 1.43 \times 10^{-2} \mathrm{mGy} \mathrm{h}^{-1} \mathrm{~mm}^{2} \mathrm{~s}=27.3 \times 10^{4} \mathrm{mGy} \mathrm{g}^{-1} \mathrm{~h}^{-1}
$$


The desired neutron dose rate based on an exposure time of $24 \mathrm{~h} /$ day is

$$
D \mathrm{n}=1 \mathrm{mGy} \div 24 \mathrm{~h}=4.2 \times 10^{-2} \mathrm{mGy} \mathrm{h}^{-1}
$$

Thus, the required amount of ${ }^{252} \mathrm{Cf}$ is

$$
{ }^{252} \mathrm{Cf}=4.2 \times 10^{-2} \mathrm{mGy} \mathrm{h}^{-1} \div\left(27.3 \times 10^{4} \mathrm{mGy} \mathrm{g}^{-1} \mathrm{~h}^{-1}\right)=15.4 \times 10^{-8} \mathrm{~g}
$$

The required activity of ${ }^{252} \mathrm{Cf}$ is

$$
\begin{aligned}
& { }^{252} \mathrm{Cf} \mathrm{Bq}=(\ln 2 \div \mathrm{T} \mathrm{s}) \times\left(\mathrm{W} \mathrm{g} \div \mathrm{M} \mathrm{g} \mathrm{mol}^{-1}\right) \times \mathrm{N}_{\mathrm{A}} \mathrm{mol}^{-1} \\
& =\left(0.693 \div\left(8.3 \times 10^{7} \mathrm{~s}\right)\right) \times\left(15.4 \times 10^{-8} \mathrm{~g} \div 252 \mathrm{~g} \mathrm{~mol}^{-1}\right) \times 6.0 \times 10^{23} \mathrm{~mol}^{-1} \\
& =3.1 \times 10^{6} \mathrm{~s}^{-1}=3.1 \times 10^{6} \mathrm{~Bq}=3.1 \mathrm{MBq}
\end{aligned}
$$

where, $\mathrm{T}$ is the half-life (s), $\mathrm{W}$ is the weight $(\mathrm{g}), \mathrm{M}$ is the molar mass $\left(\mathrm{g} \mathrm{mol}^{-1}\right)$, and $\mathrm{N}_{\mathrm{A}}$ is Avogadro's constant $\left(\mathrm{mol}^{-1}\right)$.

The unregulated sealed source containing $3.7 \mathrm{MBq}^{252} \mathrm{Cf}$ was delivered on 17 March 2020 from Japan Radioisotope Association (Tokyo, Japan). The ${ }^{252} \mathrm{Cf}$ was used in accordance with the Recommendations for Regulation on Prevention of Ionizing Radiation Hazards, compiled by the Prevention of Ionizing Radiation Hazards Committee of Gunma University, Showa Campus.

\subsection{Calculation of Dose Distribution}

To determine the quantity of ${ }^{252} \mathrm{Cf}$ necessary to achieve $1 \mathrm{mGy} /$ day, a series of Monte Carlo simulations were conducted using the Particle and Heavy Ion Transport code System (PHITS) version $3.17[25,26]$.

\subsection{Measurement of Dose Rate}

The dosimeter (radiophoto-luminescence EN, Chiyoda Technol Co., Tokyo, Japan) was inserted into a special holder (Adachi Factory, Gunma, Japan) (Figure 2) and attached to an octagonal rotor as same as sample position with and without ${ }^{252} \mathrm{Cf}$ for $24 \mathrm{~h}$. The alpha rays generated by the interaction of neutrons with special filters consisted of high density polyethylene and boron nitride, and anti-jump protons generated by the reaction of neutrons with hydrogen atoms are used in the Wide-range Neutron Pit System (Chiyoda Technol Co., Tokyo, Japan). The neutron dose rate was measured indirectly by alpha rays and protons, and analyzed by Chiyoda Technol Co. using ISO8529. The data presented here are from three individual experiments.

\subsection{Measurement of Gravity Using Accelerometer}

A 3D accelerometer (ADXL335, Analog Devices, Norwood, MA, USA) was used to measure the gravitational accelerations at the sample position along the $\mathrm{X}, \mathrm{Y}$, and $\mathrm{Z}$ directions in the octagonal rotor. The accuracy of this sensor is $\pm 0.0069 \mathrm{G}$. The gravitational accelerations were analyzed using original software (Matsuo Industries, Inc., Aichi, Japan).

\subsection{Measurement of Temperature}

A K-type thermometer (K-H0.1X1P, Ninomiya Electric Wire Co., Kanagawa, Japan) and a data logger (NR-600, KEYENCE Co., Osaka, Japan) were used to measure and record the temperatures of the centrifuge motor and the incubator including the device.

\subsection{Statistical Analysis}

Statistical analysis was performed using the Student $t$-test. $p$-values of less than 0.05 were considered statistically significant in comparing samples. 
A

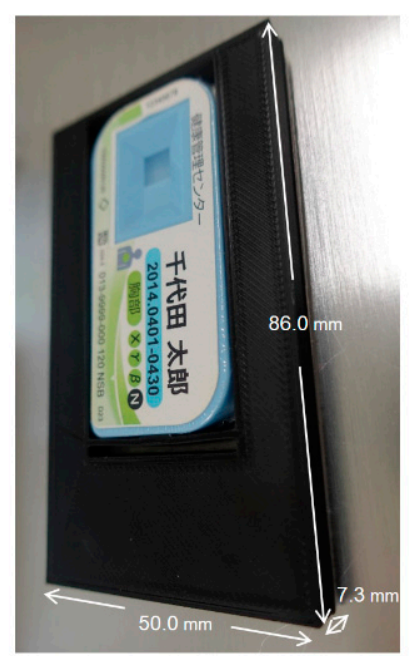

$\mathrm{B}$

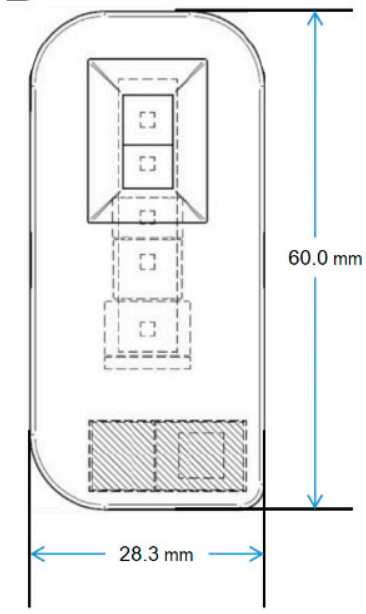

C

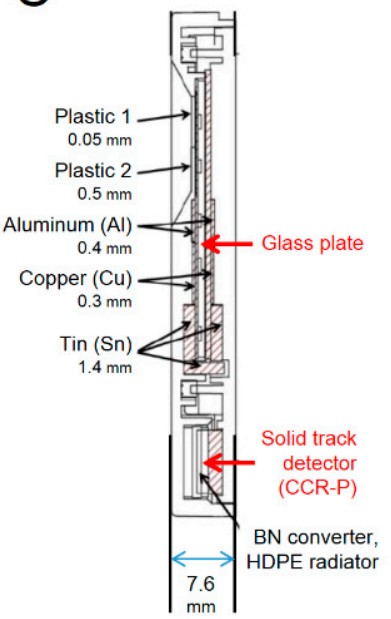

Figure 2. Glass badge dosimeter unit. (A) Overview of dosimeter in a special holder. (B) Front view of dosimeter's internal structure. (C) Side view of dosimeter's internal structure (technical data from Chiyoda Technol Co., Tokyo, Japan).

\section{Results}

\subsection{Simulation of Flatness and Symmetry in the Irradiation Fields}

The dose distribution of the samples was uniform along the $X$ and $Y$ axes (Figure 3). The assumed radius of the center was 32, 50, and $100 \mathrm{~mm}$ in the square, hexagonal, and octagonal rotor (Figure 3A). The square, hexagonal, and octagonal rotors took two, four, and six DCCs, respectively, in addition to a dosimeter and an accelerometer. The dose rate is inversely proportional to the square of the distance from the radiation source (Figure 3B). When it is away from the center in the $\mathrm{X}$ and $\mathrm{Y}$ directions, the relative dose rate of the DCC was shown in Figure 3C. The radiation dose distribution was simulated with PHITS for each rotor (Figure 3D). These results suggest that the octagonal rotor is the ideal choice for uniform dose distribution of radiation. The radiation covers a greater total DCC area with the octagonal rotor than with the hexagonal rotor, which in turn achieves more total area radiation coverage than the square rotor (Figure 3E). Based on the data, we have decided to adopt the octagonal rotor in SwiNG.

The estimated data in Table 2 confirm that the dose uniformly covers the DCC area (Figure 3C). With point a in Figure 3B being the intersection of the $X$ and $Y$ axes and receiving $100 \%$ of the dose, the difference in dose delivery between point $b$ (the short end) and point $a$ (the center) is less than $3 \%$, and the difference in dose delivery between point $\mathrm{c}$ (the most distant long-end point) and point $\mathrm{a}$ is less than $10 \%$, confirming uniform dose delivery (Table 2).

Table 2. Theoretical neutron dose rate of $3.7 \mathrm{MBq}{ }^{252} \mathrm{Cf}$.

\begin{tabular}{cccc}
\hline Position of DCC ${ }^{*}$ in Octagonal Rotor & Distance from ${ }^{252}$ Cf & Theoretical Dose Rate $^{\dagger}$ & Relative Value \\
\hline $\mathrm{a}$ (center) & $100.0 \mathrm{~mm}$ & $1.23 \pm 0.18 \mathrm{mGy} /$ day & 100.0 \\
\hline $\mathrm{b}$ (short end) & $101.5 \mathrm{~mm}$ & $1.19 \pm 0.18 \mathrm{mGy} /$ day & 97.1 \\
\hline $\mathrm{c}$ (long end) & $105.1 \mathrm{~mm}$ & $1.11 \pm 0.17 \mathrm{mGy} /$ day & 90.5 \\
\hline
\end{tabular}

${ }^{*}$ See Figures $1 \mathrm{~B}$ and $2 \mathrm{C} .{ }^{+}$Nominal value $\pm 15 \%$. 
A i

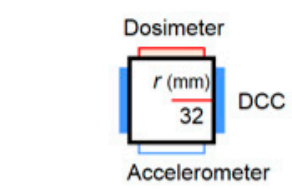

B

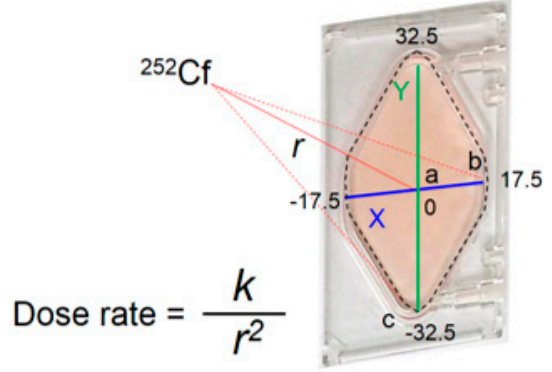

ii

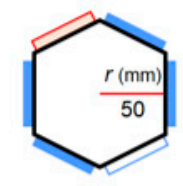

iii

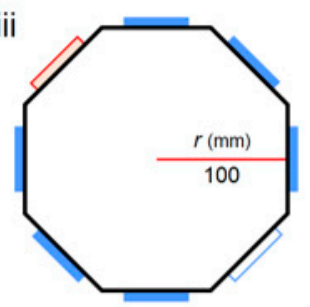

C

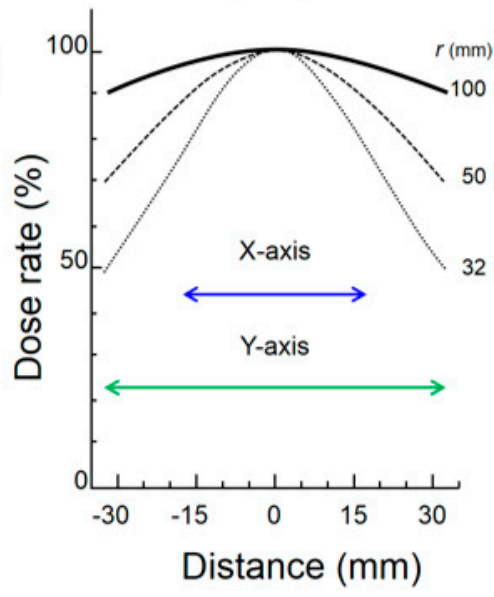

D

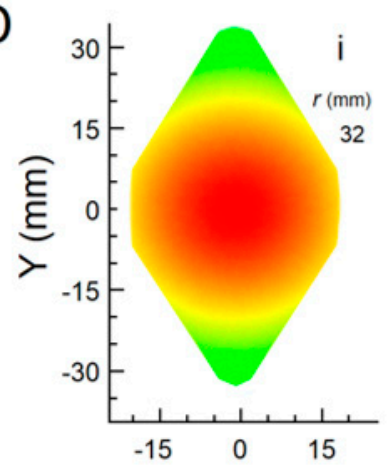

E
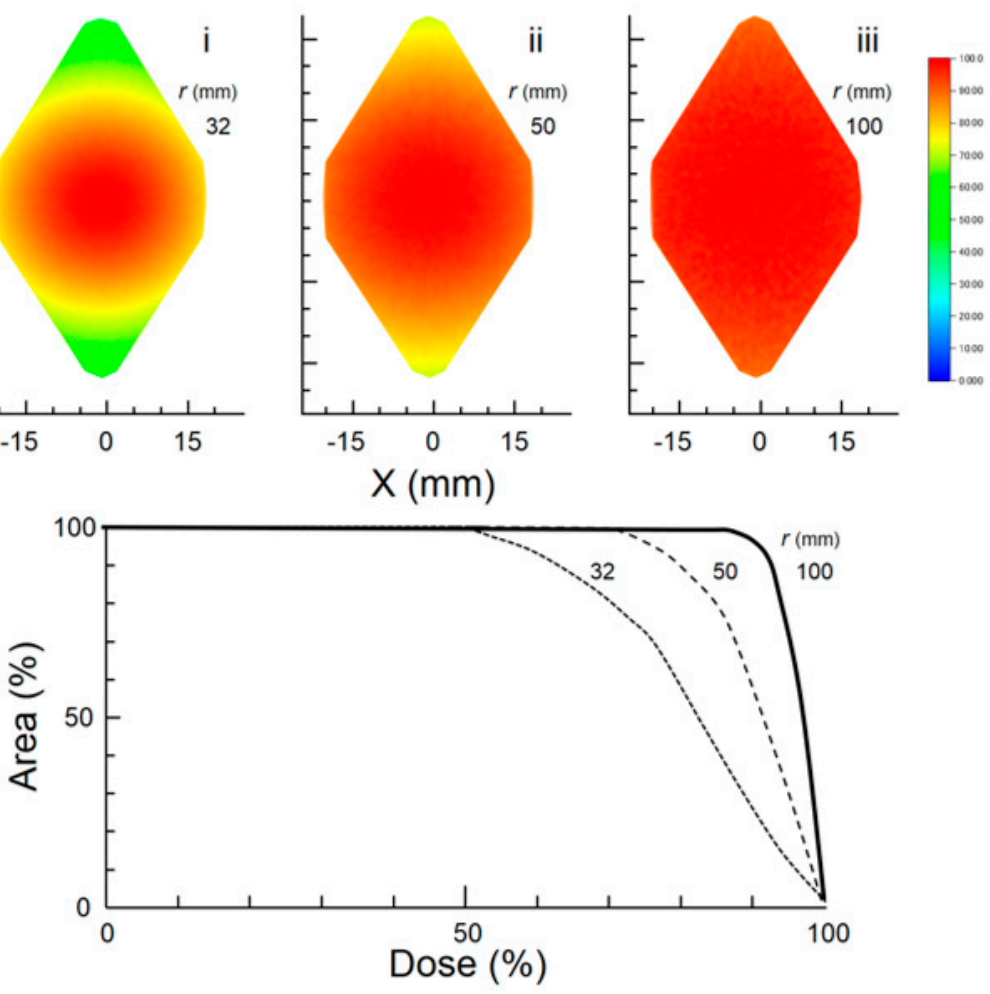

Figure 3. Theoretical radiation dose against rotor size. (A) Rotor: (i) square, (ii) hexagonal, and (iii) octagonal. (B) DCC. Dashed lines indicate actual positions of cells in a culture chamber, where " $a$ " is the center, " $b$ " is the short end, and " $c$ " is the long end of the DCC. (C) Relative dose against distance from the intersection of the $X$ and $Y$ axes; the relative dose is $100 \%$ at the intersection of $X$ and $Y$. (D) Dose distribution simulated with PHITS. (E) Dose area histogram. 


\subsection{Measurement of Dose Rate}

The measured dose rates were comparable with the theoretical dose rate about $1 \mathrm{mGy} /$ day at the center of the sample in the octagonal device with ${ }^{252} \mathrm{Cf}$ (No. 2) within the nominal range (Tables 2 and 3 ). The dose rate of $\gamma$-ray by the disintegration of ${ }^{252} \mathrm{Cf}$ was $0.5 \pm 0.1 \mathrm{mGy} /$ day at the sample position.

Table 3. Using glass badge, measured radiation dose equivalent at the control sample and the irradiation sample position of SwiNG for $24 \mathrm{~h}$.

\begin{tabular}{ccc}
\hline & Control Samples & Irradiation Samples \\
\hline Incubator of SwiNG $^{*}$ & No. 1 & No. 2 \\
\hline Neutron $^{*}$ & ND & $10.8 \pm 0.0 \mathrm{mSv}$ \\
\hline Total dose rate $^{\dagger}$ & ND & $1.08 \pm 0.00 \mathrm{mGy} /$ day \\
\hline
\end{tabular}

Measurement date, 18-21 March, 2020. ${ }^{*} 1 \mathrm{~cm}$ dose equivalent. ND, not detected. ${ }^{\dagger}$ The dose rate was determined from the dose equivalent. The radiation weighting factor of neutron $\left({ }^{252} \mathrm{Cf}, 2.1 \mathrm{MeV}\right)$ was calculated as 10 [27].

Since the control samples in the device without ${ }^{252} \mathrm{Cf}$ (No. 1) are ca 800-1000 mm away from the ${ }^{252} \mathrm{Cf}$ in No. 2 incubator, the dose rate of control sample is assumed at least $1 / 64-1 / 100$ that of the irradiation sample in the device with ${ }^{252} \mathrm{Cf}$ (No. 2). In fact, the dose rate of control group in the device without ${ }^{252} \mathrm{Cf}$ (No. 1) was below the detection limit. The data of environmental radiation monitoring around SwiNG was shown in Table 4.

Table 4. The environmental radiation monitoring around SwiNG.

\begin{tabular}{cccc}
\hline Position & $\gamma$-ray & Neutron & Total \\
\hline The surface of SwiNG & $1.5 \mu \mathrm{Sv} / \mathrm{h}$ & $18.4 \mu \mathrm{Sv} / \mathrm{h}$ & $19.9 \mu \mathrm{Sv} / \mathrm{h}$ \\
\hline $1 \mathrm{~m}$ distance from ${ }^{252} \mathrm{Cf}$ & $0.3 \mu \mathrm{Sv} / \mathrm{h}$ & $6.7 \mu \mathrm{Sv} / \mathrm{h}$ & $7.0 \mu \mathrm{Sv} / \mathrm{h}$ \\
\hline $2 \mathrm{~m}$ distance from ${ }^{252} \mathrm{Cf}$ & $0.2 \mu \mathrm{Sv} / \mathrm{h}$ & $2.5 \mu \mathrm{Sv} / \mathrm{h}$ & $2.7 \mu \mathrm{Sv} / \mathrm{h}$ \\
\hline
\end{tabular}

\subsection{Simulation of Flatness and Symmetry in the Gravity Fields}

For the octagonal rotor, the assumed distances from the center axis of the centrifuge were $100 \mathrm{~mm}$ and 100-101 mm along the $Y$ and $X$ axes of the sample. The theoretical relative centrifugal force (RCF) distributions of the samples were equal along the $\mathrm{Y}$ axis and almost equal along the $\mathrm{X}$ axis.

\subsection{Measurement of Gravity}

The simulator could reproduce from $\mu G$ up to $2 G$. At each rotation speed, the theoretical and measured RCFs of SwiNG nos. 1 and 2 were almost the same (Table 5 and Figure 4). After about $20 \mathrm{~s}$, the measured integrated RCF was very stable (Figure 4).

Table 5. Simulated relation between centrifuge rotation and gravity at the sample position of SwiNG.

\begin{tabular}{|c|c|c|c|c|}
\hline \multirow{2}{*}{$\begin{array}{c}\text { Rotary Speed of } \\
\text { Motor } 1 \text { (Centrifuge) * }\end{array}$} & \multirow{2}{*}{$\begin{array}{l}\text { Theoretical RCF }{ }^{+} \\
(r=100-101 \mathrm{~mm})\end{array}$} & \multicolumn{2}{|c|}{ Measured RCF $\ddagger$} & \multirow{2}{*}{ Simulation } \\
\hline & & No. 1 & No. 2 & \\
\hline $0.0 \mathrm{rpm}$ & $\sim \mu G$ & $0.01 \pm 0.00 G$ & $0.01 \pm 0.00 G$ & interplanetary space \\
\hline $38.4 \mathrm{rpm}$ & $0.165-0.167 G$ & $0.17 \pm 0.00 G$ & $0.17 \pm 0.00 G$ & on the Moon \\
\hline $58.1 \mathrm{rpm}$ & $0.377-0.381 G$ & $0.38 \pm 0.00 G$ & $0.39 \pm 0.00 G$ & on Mars \\
\hline $94.5 \mathrm{rpm}$ & $0.998-1.008 G$ & $1.01 \pm 0.00 G$ & $1.01 \pm 0.00 G$ & on the Earth \\
\hline $133.0 \mathrm{rpm}$ & $1.978-1.997 G$ & $1.98 \pm 0.01 G$ & $2.00 \pm 0.00 G$ & hypergravity \\
\hline
\end{tabular}

${ }^{*}$ The rotary speeds of motors 2 and 3 were 13.0 and $11.0 \mathrm{rpm}$, respectively. ${ }^{\dagger} \mathrm{RCF}$ (Relative centrifugal force) $=1.118$

$\times \mathrm{r}[\mathrm{mm}] \times \mathrm{N}^{2}[\mathrm{rpm}] \times 10^{-6} . \ddagger$ The presented results are the mean and SD of three independent experiments. 


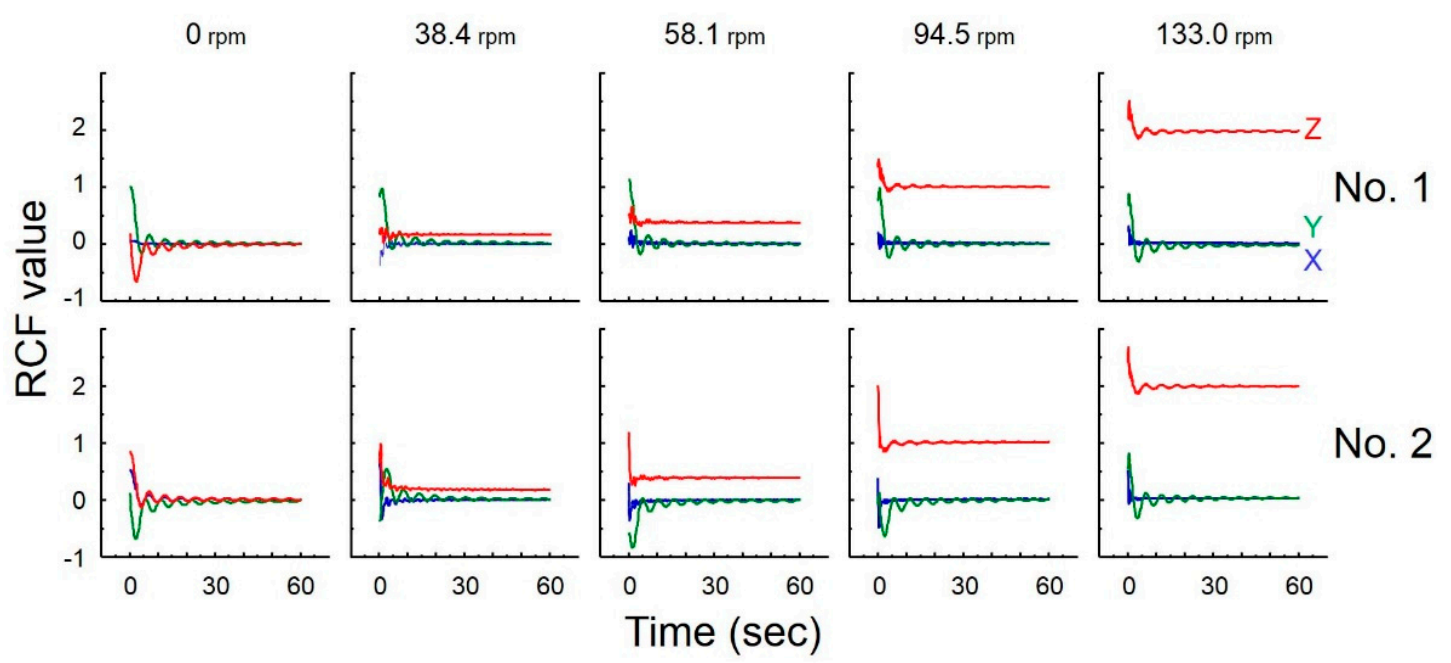

Figure 4. Measured integrated RCF for different rotary speeds of motor 1 during 1-min rotation. The rotary speeds of motors 2 and 3 were 13.0 and $11.0 \mathrm{rpm}$, respectively.

\subsection{Measurement of Temperature}

Although the temperature of the centrifuge motor at $133.0 \mathrm{rpm}$ was the maximum of $38^{\circ} \mathrm{C}$, the temperature in the incubator including the device was $37 \pm 0.2{ }^{\circ} \mathrm{C}$ when set to $37^{\circ} \mathrm{C}$ (data not shown). As the sample holder of the rotor was made of plastic (polybutylene terephthalate- $30 \%$ glass fiber, PBT-GF30), heat from the motor did not conduct to the samples.

\section{Discussion}

The new compact simulator, SwiNG, was developed to expose samples to low-dose-rate neutron radiation (1 mGy/day) from ${ }^{252} \mathrm{Cf}$ under partial gravity using a centrifuge $(\mathrm{r}=100 \mathrm{~mm})$ in a 3D clinostat (Figure 1). Using a centrifuge $(\mathrm{r}=100 \mathrm{~mm})$, the PHITS simulation confirmed our system's ability to provide uniform dose distribution (Figure 3Diii). In our new system, radiation source is located at the center of the chamber in the rotor, and surface of the samples are constantly facing to the radiation source. Although we measured the dose rate at center of sample position only at $1 G$ (Table 3), it is unlikely that the dose will change under any gravity for each of the centrifuge cases. The reasons were that the distance between the neutron source and the sample is constant at $100 \mathrm{~mm}$. Further, motors 2 and 3 are constantly rotating under each gravitational condition, so that the effects of scattered radiation in the incubator is uniform on the samples. Interesting results have been reported with mice exposed to low-dose neutrons using ${ }^{252} \mathrm{Cf}$ at CSU [28-30]. New discoveries can be expected with our new simulator system.

We confirmed that the system can instantaneously change the gravity environment (Figure 4) in addition to providing low-dose radiation exposure. The rotation speed of the centrifuge can be changed in accordance with the user's purpose and choice of samples to simulate partial gravity. Moreover, the simulator can reproduce $\mu G$, the Earth control of $1 G$, and hypergravity condition (up to $2 G$ ) of launch and landing to Earth. Another advantage of our new system is that six samples can be exposed to radiation at the same time.

We are planning to use DCCs for in vitro biological experiments such as DNA damage, chromosomal aberrations, gene expression changes, and so on using cultured cells. The chamber can be completely filled with a medium (without bubbles) to eliminate shear stress on the cells or minimize it as much as possible [31]. Shear stress is reported to be almost negligible in the absence of air bubbles in a slowly rotating medium [32]. We have already validated DCCs using human fibroblasts and lymphoblasts cultured with a $\mathrm{CO}_{2}$-independent medium (Thermo Fischer Scientific, Waltham, MA, USA) and found no problems with cell growth under atmospheric conditions [17,33,34]. This DCC chamber can exchange the gas thorough the special gas permeable membrane [23]. Therefore, the oxygen available inside the DCC is available from the atmosphere and is sufficient for cell metabolism, and $\mathrm{CO}_{2}$ will be supplied from 
buffered medium. Furthermore, the temperature of the sample can be easily controlled and maintained under suitable conditions in the incubators with a cooling function. Besides human cell cultures, the simulator can be used for microorganisms such as bacteria, yeast, Pyrocystis noctiluca or Dictyostelium discoideum which has been used in past ground-based experiments and/or space experiments [35-40].

To confirm experimental results obtained from in vitro experiments with our simulating system, it will be important to perform in vivo experiments with partial gravity such as quadrupedal unloading [41-44] on the ground. The effects should be tested either in a proper centrifuge experiment on the ISS, such as the Cell Biology Equipment Facility (CBEF) [45] and mouse habitat unit (MHU) cage [46], or on the actual surfaces of the Moon and Mars.

\section{Conclusions}

We developed the SwiNG for simulator of the environments on the Moon and Mars with low-dose-rate (1 mGy/day) irradiation and partial gravity, and evaluated the physical performance of the hardware using theoretical and measured values of neutron dose rate and averaged gravity at the sample position in octagonal rotator. The simulator is highly convenient for space biology research because of the limited availability of space experiments. The basic data from ground experiments using our system are expected to help develop a new biological parameter for evaluating human health risks in space radiation involving radiological protection.

Author Contributions: Conceptualization, A.T., K.T. (Kazuomi Takeuchi), S.T., Y.Y., J.H., A.H., M.H. and Y.S.; methodology, M.T. and A.N.; validation, K.T. (Kazuomi Takeuchi), S.T., K.T. (Kunihito Takeuchi), T.T. and S.Y.; formal analysis, S.Y.; investigation, S.Y., S.Z. and F.N.L.G.; resources, K.T. (Kazuomi Takeuchi), S.T., T.A., K.T. (Kunihito Takeuchi), T.T. and S.Y.; writing — original draft preparation, S.Z., F.N. and A.T.; writing-review and editing, S.T., M.T., A.N. and M.H.; supervision, Y.S.; project administration, A.T.; funding acquisition, A.T. and M.H. All authors have read and agreed to the published version of the manuscript.

Funding: This research was funded by the Institute of Space and Astronautical Science, JAXA Front Loading Study, MEXT Grant-in-Aid for Scientific Research on Innovative Areas, Japan “Living in Space" (grant nos. JP15H05945, JP15H05935, and JP15K21745) and NASA Space Biology Program (grant no. 80NSSC19K0133).

Acknowledgments: We thank Kei Shibuya (Gunma University) for allowing us to use ${ }^{252} \mathrm{Cf}$ at Gunma University, and Yukihiko Sejimo and Miyako Kido (Chiyoda Technol Co.) for conducting the ${ }^{252} \mathrm{Cf}$ dosimetry. Mark Kurban from Edanz Group (www.edanzediting.com/ac) edited a draft of this manuscript.

Conflicts of Interest: The authors declare no conflict of interest.

\section{References}

1. Takahashi, A.; Ikeda, H.; Yoshida, Y. Role of high-linear energy transfer radiobiology in space radiation exposure risk. Int. J. Part. Ther. 2018, 5, 151. [CrossRef] [PubMed]

2. Furukawa, S.; Nagamatsu, A.; Nenoi, M.; Fujimori, A.; Kakinuma, S.; Katsube, T.; Wang, B.; Tsuruoka, C.; Shirai, T.; Nakamura, A.J.; et al. Space radiation biology for “Living in Space”. BioMed Res. Int. 2020, 2020, 4703286. [CrossRef] [PubMed]

3. Simonsen, L.C.; Slaba, T.C.; Guida, P.; Rusek, A. NASA's first ground-based Galactic Cosmic Ray Simulator: Enabling a new era in space radiobiology research. PLoS Biol. 2020, 18, e3000669. [CrossRef] [PubMed]

4. Borak, T.B.; Heilbronn, L.H.; Krumland, N.; Weil, M.M. Design and dosimetry of a facility to study health effects following exposures to fission neutrons at low dose rates for long durations. Int. J. Radiat. Biol. 2019. [CrossRef] [PubMed]

5. Norbury, J.; Slaba, T. Space radiation accelerator experiments: The role of neutrons and light ions. Life Sci. Space Res. 2014, 3, 90-94. [CrossRef]

6. Nelson, G.A. Space radiation and human exposures, a primer. Radiat. Res. 2016, 185, 349-358. [CrossRef]

7. Chatterjee, A.; Borak, T.H. Physical and biological studies with protons and HZE particles in a NASA supported research center in radiation health. Phys. Med. 2001, 17, 59-66. 
8. Manzano, A.; Herranz, R.; den Toom, L.A.; Te Slaa, S.; Borst, G.; Visser, M.; Medina, F.J.; van Loon, J.J.W.A. Novel, Moon and Mars, partial gravity simulation paradigms and their effects on the balance between cell growth and cell proliferation during early plant development. NPJ Microgravity 2018, 4, 9. [CrossRef] [PubMed]

9. Risin, D.; Pellis, N.R. Modeled microgravity inhibits apoptosis in peripheral blood lymphocytes. Vitr. Cell Dev. Biol. Anim. 2001, 37, 66-72. [CrossRef]

10. Canova, A.; Fiorasi, F.; Mognato, M.; Grifalconi, M.; Reddi, E.; Russo, A.; Celotti, L. Modeled microgravity affects cell response to ionizing radiation and increases genomic damage. Radiat. Res. 2005, 163, 191-199. [CrossRef]

11. Mognato, M.; Celotti, L. Modeled microgravity affects cell survival and HPRT mutant frequency, but not the expression of DNA repair genes in human lymphocytes irradiated with ionising radiation. Mutat. Res. 2005, 578, 417-429. [CrossRef] [PubMed]

12. Mognato, M.; Girardi, C.; Fabris, S.; Celotti, L. DNA repair in modeled microgravity: Double strand break rejoining activity in human lymphocytes irradiated with $\gamma$-rays. Mutat. Res. 2009, 663, 32-39. [CrossRef] [PubMed]

13. Dang, B.; Yang, Y.; Zhang, E.; Li, W.; Mi, X.; Meng, Y.; Yan, S.; Wang, Z.; Wei, W.; Shao, C.; et al. Simulated microgravity increases heavy ion radiation-induced apoptosis in human B lymphoblasts. Life Sci. 2014, 97, 123-128. [CrossRef]

14. Girardi, C.; De Pittà, C.; Casara, S.; Sales, G.; Lanfranchi, G.; Celotti, L.; Mognato, M. Analysis of miRNA and mRNA expression profiles highlights alterations in ionizing radiation response of human lymphocytes under modeled microgravity. PLoS ONE 2012, 7, e31293. [CrossRef] [PubMed]

15. Beck, M.; Moreels, M.; Quintens, R.; Abou-El-Ardat, K.; El-Saghire, H.; Tabury, K.; Michaux, A.; Janssen, A.; Neefs, M.; Van Oostveldt, P.; et al. Chronic exposure to simulated space conditions predominantly affects cytoskeleton remodeling and oxidative stress response in mouse fetal fibroblasts. Int. J. Mol. Med. 2014, 34, 606-615. [CrossRef]

16. Ikeda, H.; Souda, H.; Puspitasari, A.; Held, K.D.; Hidema, J.; Nikawa, T.; Yoshida, Y.; Kanai, T.; Takahashi, A. A new system for three-dimensional clinostat synchronized $X$-irradiation with a high-speed shutter for space radiation research. Biol. Sci. Space 2016, 30, 8-16. [CrossRef]

17. Ikeda, H.; Souda, H.; Puspitasari, A.; Held, K.D.; Hidema, J.; Nikawa, T.; Yoshida, Y.; Kanai, T.; Takahashi, A. Development and performance evaluation of a three-dimensional clinostat synchronized heavy-ion irradiation system. Life Sci. Space Res. 2017, 12, 51-60. [CrossRef]

18. Shen-Miller, J.; Hinchman, R.; Gordon, S.A. Thresholds for georesponse to acceleration in gravity-compensated Avena seedlings. Plant Physiol. 1968, 43, 338-344. [CrossRef]

19. Lyon, C.J. Lateral transport of auxin mediated by gravity in the absence of special georeceptor tissue. Plant Physiol. 1971, 48, 642-644. [CrossRef]

20. Brown, A.H.; Dahl, A.O.; Chapman, D.K. Limitation on the use of the horizontal clinostat as a gravity compensator. Plant Physiol. 1976, 58, 4. [CrossRef] [PubMed]

21. Laurinavicius, R.; Svegzdiene, D.; Buchen, B.; Sievers, A. Determination of the threshold acceleration for the gravitropic stimulation of cress roots and hypocotyls. Adv. Space Res. 1998, 21, 1203-1207. [CrossRef]

22. Galland, P.; Finger, H.; Wallacher, Y. Gravitropism in Phycomyces: Threshold determination on a clinostat centrifuge. J. Plant Physiol. 2004, 161, 733-739. [CrossRef]

23. Tanigawa, N.; Yano, S.; Higashibata, A.; Tsuchiya, Y.; Tanii, H.; Ando, N.; Kubota, K.; Nagase, M. Development and validation of a closed chamber for cell culture experiments in space. Biol. Sci. Space 2014, 28, 1-5. [CrossRef]

24. Stoddard, D.H.; Hootman, H.E. ${ }^{252}$ Cf Shielding Guide, DP-1246; Savannah River Laboratory: Aiken, SC, USA, 1971.

25. Iwamoto, Y.; Sato, T.; Hashimoto, S.; Ogawa, T.; Furuta, T.; Abe, S.; Kai, T.; Matsuda, N.; Hosoyamada, R.; Niita, K. Benchmark study of the recent version of the PHITS code. J. Nucl. Sci. Technol. 2017, 54, 617-635. [CrossRef]

26. Sato, T.; Iwamoto, Y.; Hashimoto, S.; Ogawa, T.; Furuta, T.; Abe, S.; Kai, T.; Tsai, P.-E.; Matsuda, N.; Iwase, H.; et al. Features of Particle and Heavy Ion Transport code System (PHITS) version 3.02. J. Nucl. Sci. Technol. 2018, 55, 684-690. [CrossRef] 
27. Valentin, J. Relative biological effectiveness (RBE), quality factor $(Q)$, and radiation weighting factor $\left(w_{R}\right)$ : ICRP Publication 92. Ann. ICRP 2003, 33, 1-121.

28. Acharya, M.M.; Baulch, J.E.; Klein, P.M.; Baddour, A.A.D.; Apodaca, L.A.; Kramár, E.A.; Alikhani, L.; Garcia, C., Jr.; Angulo, M.C.; Batra, R.S.; et al. New concerns for neurocognitive function during deep space exposures to chronic, low dose-rate, neutron radiation. eNeuro 2019, 6, ENEURO.0094-19.2019. [CrossRef]

29. Britten, R.A.; Duncan, V.D.; Fesshaye, A.S.; Wellman, L.L.; Fallgren, C.M.; Sanford, L.D. Sleep fragmentation exacerbates executive function impairments induced by protracted low dose rate neutron exposure. Int. J. Radiat. Biol. 2019. [CrossRef]

30. Perez, R.E.; Younger, S.; Bertheau, E.; Fallgren, C.M.; Weil, M.M.; Raber, J. Effects of chronic exposure to a mixed field of neutrons and photons on behavioral and cognitive performance in mice. Behav. Brain Res. 2020, 379, 112377. [CrossRef]

31. Ikeda, H.; Muratani, M.; Hidema, J.; Hada, M.; Fujiwara, K.; Souda, H.; Yoshida, Y.; Takahashi, A. Expression profile of cell cycle-related genes in human fibroblasts exposed simultaneously to radiation and simulated microgravity. Int. J. Mol. Sci. 2019, 20, 4791. [CrossRef]

32. Todd, P. Physical effects at the cellular level under altered gravity conditions. Adv. Space Res. 1992, 12, 43-49. [CrossRef]

33. Hada, M.; Ikeda, H.; Rhone, J.R.; Beitman, A.J.; Plante, I.; Souda, H.; Yoshida, Y.; Held, K.D.; Fujiwara, K.; Saganti, P.B.; et al. Increased chromosome aberrations in cells exposed simultaneously to simulated microgravity and radiation. Int. J. Mol. Sci. 2019, 20, 43. [CrossRef]

34. Yamanouchi, S.; Rhone, J.R.; Mao, J.-H.; Fujiwara, K.; Saganti, P.B.; Takahashi, A.; Hada, M. Simultaneous exposure of cultured human lymphoblastic cells to simulated microgravity and radiation increases chromosome aberrations. Life 2020, 10, 187. [CrossRef] [PubMed]

35. Ohnishi, T.; Takahashi, A.; Okaichi, K.; Ohnishi, K.; Matsumoto, H.; Takahashi, S.; Yamanaka, H.; Nakano, T.; Nagaoka, S. Cell growth and morphology of Dictyostelium discoideum in space environment. Biol. Sci. Space 1997, 11, 29-34. [CrossRef]

36. Takahashi, A.; Ohnishi, K.; Fukui, M.; Nakano, T.; Yamaguchi, K.; Nagaoka, S.; Ohnishi, T. Mutation frequency of Dictyostelium discoideum spores exposed to the space environment. Biol. Sci. Space 1997, 11, 81-86. [CrossRef]

37. Takahashi, A.; Ohnishi, K.; Takahashi, S.; Masukawa, M.; Sekikawa, K.; Amano, T.; Nakano, T.; Nagaoka, S.; Ohnishi, T. Differentiation of Dictyostelium discoideum vegetative cells into spores during Earth orbit in space. Adv. Space Res. 2001, 28, 549-553. [CrossRef]

38. Takahashi, A.; Ohnishi, K.; Takahashi, S.; Masukawa, M.; Sekikawa, K.; Amano, T.; Nakano, T.; Nagaoka, S.; Ohnishi, T. The effects of microgravity on induced mutation in Escherichia coli and Saccharomyces cerevisiae. Adv. Space Res. 2001, 28, 555-561. [CrossRef]

39. Takahashi, A.; Ohnishi, K.; Yokota, A.; Kumagai, T.; Nakano, T.; Ohnishi, T. Mutation frequency of plasmid DNA and Escherichia coli following long-term space flight on Mir. J. Radiat. Res. 2002, 43, S137-S140. [CrossRef]

40. Hauslage, J.; Cevik, V.; Hemmersbach, R. Pyrocystis noctiluca represents an excellent bioassay for shear forces induced in ground-based microgravity simulators (clinostat and random positioning machine). NPJ Microgravity 2017, 3, 12. [CrossRef]

41. Wagner, E.B.; Granzella, N.P.; Saito, H.; Newman, D.J.; Young, L.R.; Bouxsein, M.L. Partial weight suspension: A novel murine model for investigating adaptation to reduced musculoskeletal loading. J. Appl. Physiol. 2010, 109, 350-357. [CrossRef]

42. Wilson, J.M.; Krigsfeld, G.S.; Sanzari, J.K.; Wagner, E.B.; Mick, R.; Kennedy, A.R. Comparison of hindlimb unloading and partial weight suspension models for spaceflight-type condition induced effects on white blood cells. Adv. Space Res. 2012, 49, 237-248. [CrossRef] [PubMed]

43. Ellman, R.; Spatz, J.; Cloutier, A.; Palme, R.; Christiansen, B.A.; Bouxsein, M.L. Partial reductions in mechanical loading yield proportional changes in bone density, bone architecture, and muscle mass. J. Bone Miner. Res. 2013, 28, 875-885. [CrossRef] [PubMed]

44. Mortreux, M.; Ko, F.C.; Riveros, D.; Bouxsein, M.L.; Rutkove, S.B. Longitudinal time course of muscle impairments during partial weight-bearing in rats. NPJ Microgravity 2019, 5, 20. [CrossRef] 
45. Ishioka, N.; Suzuki, H.; Asashima, M.; Kamisaka, S.; Mogami, Y.; Ochiai, T.; Aizawa-Yano, S.; Higashibata, A.; Ando, N.; Nagase, M.; et al. Development and verification of hardware for life science experiments in the Japanese Experiment Module "Kibo" on the International Space Station. J. Gravit. Physiol. 2004, 11, 81-91.

46. Shiba, D.; Mizuno, H.; Yumoto, A.; Shimomura, M.; Kobayashi, H.; Morita, H.; Shimbo, M.; Hamada, M.; Kudo, T.; Shinohara, M.; et al. Development of new experimental platform 'MARS'-Multiple Artificial-gravity Research System-to elucidate the impacts of micro/partial gravity on mice. Sci. Rep. 2017, 7, 10837. [CrossRef]

Publisher's Note: MDPI stays neutral with regard to jurisdictional claims in published maps and institutional affiliations.

(C) 2020 by the authors. Licensee MDPI, Basel, Switzerland. This article is an open access article distributed under the terms and conditions of the Creative Commons Attribution (CC BY) license (http://creativecommons.org/licenses/by/4.0/). 